\title{
A Systematic Review on Nerve-Related Adverse Effects following Mandibular Nerve Block Anesthesia
}

\author{
Luca Aquilanti ${ }^{1}$, , Marco Mascitti ${ }^{1, *}$, Lucrezia Togni $^{1}$, Maria Contaldo ${ }^{2} \oplus$, Giorgio Rappelli ${ }^{1,3}$ \\ and Andrea Santarelli ${ }^{1,3}$ (D) \\ 1 Department of Clinical Specialistic and Dental Sciences, Università Politecnica delle Marche, Via Tronto 10/A, \\ 60126 Ancona, Italy; 1.aquilanti@pm.univpm.it (L.A.); togni.lucrezia@gmail.com (L.T.); \\ g.rappelli@staff.univpm.it (G.R.); andrea.santarelli@staff.univpm.it (A.S.) \\ 2 Multidisciplinary Department of Medical-Surgical and Dental Specialties, University of Campania "Luigi \\ Vanvitelli", Via Armanni, 5, 80138 Naples, Italy; maria.contaldo@gmail.com \\ 3 Dentistry Clinic, National Institute of Health and Science of Aging, IRCCS INRCA, Via Tronto 10/A, \\ 60126 Ancona, Italy \\ * Correspondence: m.mascitti@pm.univpm.it; Tel.: +39-071-2206-226
}

Citation: Aquilanti, L.; Mascitti, M.; Togni, L.; Contaldo, M.; Rappelli, G.; Santarelli, A. A Systematic Review on Nerve-Related Adverse Effects following Mandibular Nerve Block Anesthesia. Int. J. Environ. Res. Public Health 2022, 19, 1627. https:// doi.org/10.3390/ijerph19031627 Academic Editor: Paul B. Tchounwou

Received: 30 December 2021

Accepted: 28 January 2022

Published: 31 January 2022

Publisher's Note: MDPI stays neutral with regard to jurisdictional claims in published maps and institutional affiliations.

Copyright: (C) 2022 by the authors. Licensee MDPI, Basel, Switzerland. This article is an open access article distributed under the terms and conditions of the Creative Commons Attribution (CC BY) license (https:// creativecommons.org/licenses/by/ $4.0 /)$.

\begin{abstract}
Inferior alveolar nerve (IAN) block injections are commonly used in clinical practice, but they are not free from complications. The aim of the present systematic review is to assess the nerverelated adverse effects of IAN block anesthesia. A structured and systematic search was performed on the major electronic databases (PubMed, Cochrane Library, Web of Science, Scopus and CINAHL) for studies published in English until 30 September 2021. A total of 131 articles were identified through database searching using combinations of keywords. Fifteen papers were included and assessed for eligibility. Overall, nerve damage following an IAN block anesthesia injection is a rare occurrence, probably due to the direct nerve trauma of the needle, a neurotoxic effect of the used anesthetic solution and/or a combination of them. From a medico-legal point of view, a balanced discussion prior to nerve block anesthesia should be pursued in order to avoid patients' reluctance to undergo necessary dental treatment due to the remote eventuality of nerve injury.
\end{abstract}

Keywords: inferior alveolar nerve block; anesthesia; nerve injury; paresthesia; prolonged anesthesia; adverse effects

\section{Introduction}

The temporary decrease in the perception of pain during dental treatments is able to reduce the onset of anxiety among dental patients, and it is fundamental in clinical practice [1]. Local anesthetics are reliable and efficient drugs, but clinicians should be aware that complications may occur [2].

When performing a local anesthetic technique in a dental setting, systemic to locoregional complications may arise. According to Haas [3], adverse events due to anxiety are the most common phenomena associated with local anesthetic injection. The affected subject usually experiences syncope, but a wide range of symptoms may appear as well (e.g., hyperventilation, nausea, vomiting and heart rate or blood pressure alteration). Additionally, allergic reactions may happen, even if the incidence of allergies to amide local anesthetics is less than 1\% [4]. These manifestations should be also put in differential diagnosis with anxiety-induced events [5]. In addition, a local anesthetic may be toxic if a high concentration of the agent is reached in the bloodstream, especially if multiple injections are performed or because of an inadvertent intravascular injection [6]. Another adverse reaction, mainly associated with some anesthetic agents (e.g., prilocaine, articaine or the topical anesthetic benzocaine), is methemoglobinemia. This event is caused by an excess of anesthetic agent metabolites, resulting in systemic cyanosis [7]. Prolonged anesthesia or paresthesia of the tongue or lip has been documented as well. It is mostly 
transient, but it may become permanent with the lingual nerve more commonly affected than the inferior alveolar nerve. Other reported complications comprise: (i) facial nerve paralysis due to the inoculation of an anesthetic agent into the capsule of the parotid gland, with a transient inability to close the ipsilateral eye, with an intact corneal reflex; (ii) postinjection trismus, possibly due to hematoma formation, infection, multiple injections or an excessive volume of local anesthetics; (iii) pain from the inoculation of the local anesthetic agent, caused by the rapid injection of the anesthetic into the tissue or by the shape of the needle; (iv) post-injection infection, due to the contamination of the needle; (v) needle fracture and other complications such as edema, hematoma, gingival lesions, soft tissue injury and taste alteration $[2,3]$.

Overall, injection methods and anesthetic solutions are the most important factors when performing local anesthesia, as they play a decisive role in the success of anesthesia itself [8]. The Halstead, Vazirani-Akinosi and Gow-Gates techniques are some of the described techniques available for the anesthesia of the inferior alveolar nerve (IAN) [9]. An IAN block is commonly used in dental practice, but a high failure rate has been reported, reaching $20-47 \%[10,11]$. Even if these techniques reported different success and failure rates, they are still used on the basis of the clinical situation and practitioners' comfortability [12]. Moreover, many expediencies were proposed to enhance IAN block success rates, such as developing new anesthetics, changing the patient's position, and adjusting the drug dosage [11,13-15]. Regarding anesthetic solutions, articaine was reported as being more likely than others to be associated with paresthesia. Nevertheless, it is considered a safe local anesthetic for clinical use in dentistry since it can be used safely and effectively in both adults and children [16].

Currently, it is not possible to provide an accurate estimate of the incidence of adverse phenomena due to IAN anesthetic techniques. Thus, the aim of the present systematic review is to assess the nerve-related adverse effects of IAN block anesthetic injection techniques.

\section{Materials and Methods}

This systematic review was performed in accordance with the recommendations of the "Preferred Reporting Items for Systematic Reviews and Meta-Analyses Protocols (PRISMA-P) statement" [17]. In accordance with the guidelines, the present systematic review protocol was registered in the International Prospective Register of Systematic Reviews (PROSPERO) (registration number CRD42022282622).

\subsection{Information Sources}

A structured and systematic search was performed on the major electronic databases for studies published in the English language until 30 September 2021: PubMed, Cochrane Library, Web of Science, Scopus and CINAHL databases. Handsearching of the reference lists of included studies, relevant reviews, national clinical practice guidelines or other relevant documents was performed. Moreover, the Database of Abstracts of Reviews of Effects (DARE) was searched to examine any further existing systematic reviews and meta-analyses assessing the adverse effects related to IAN block injections.

\subsection{Search Strategy}

The following keywords were used in order to perform database searches: "mandibular", "nerve injuries", "nerve block", "adverse effects", "prolonged anesthesia", "paresthesia" and "dysesthesia", in combination with the Boolean operators "AND" and "OR". A pilot search was undertaken in order to ensure that the search strategy was effective. The study focused on the Population/Patient, Intervention, Control/Comparison, Outcome(s) (P.I.C.O.S.) criteria [18]. In particular, studies involving humans who experienced IAN block anesthesia in either a private or public dental office were included in the present review. Subjects of any age, sex, ethnicity, socio-economic status and comorbidities were considered. Studies reporting IAN block anesthesia-related adverse effects were included. The adverse effects were defined as undesirable outcomes that occur during or after the 
use of a drug or intervention but are not necessarily caused by it [19]. Any type of adverse event affecting either the mandibular or lingual nerve, or both, was examined. The primary outcome of the review was the assessment of the related adverse effects, in terms of alteration in nerve sensation, in the IAN block and their estimated incidence. The secondary outcomes were: (i) the identification of the most usual types of anesthetic drugs related to undesirable effects, as well as the concentration of their anesthetic agent; (ii) the evaluation of the most affected nerve; (iii) the hypothesized explanation of the mechanism that leads to nerve damage.

\subsection{Eligibility Criteria}

Eligible studies were (a) studies published in the English language; (b) studies published in a peer-reviewed journal; (c) studies published until 30 September 2021; (d) clinical studies; I studies reporting non-surgical nerve injuries. Studies were excluded if they were: (a) reviews, editorials, commentaries, letters, book chapters, reports on prospective ideas and futuristic scenarios (protocols included) and dissertations.

\subsection{Data Extraction}

All the eligible citations were imported into a bibliographic software or citation management system and duplicates were removed. Selected papers were then imported into Rayyan QCRI (Qatar Computing Research Institute (Data Analytics), Doha, Qatar) for screening. Two reviewers (L.A. and M.M.) carried out the evaluations independently. The very first selection was made on the basis of papers' title or abstract, and eligible ones were selected for full-text review. Titles and abstracts were screened by two independent review authors for assessment against the inclusion criteria for the review. Full-text studies that did not meet the inclusion criteria were excluded, and the reasons for exclusion were provided in the systematic review. At each stage of the study selection process, if a consensus was not reached, a third review author (A.S.) was consulted. The results of the search were reported in the final report and presented in a PRISMA flow diagram.

For the assessment of each publication, Excel spreadsheets were compiled. Data were extracted using a standardized form which included (a) authors' names and the year of publication, (b) the country in which the study was performed, (c) the study design, (d) the aim of the studI, (e) the sample size, (f) the mean age \pm standard deviation or age range, $(\mathrm{g})$ the used anesthetic solution, (h) the retrieved article main outcomes and (i) the retrieved article secondary outcomes. Both authors compared their assessments and confirmed the data on the basis of the compiled spreadsheets. In case of doubt, concerning the study data, the two reviewers resolved disagreements by discussion. In the case of doubt, a third reviewer solved discrepancies.

\subsection{Quality Assessment}

The methodological quality of the studies included was assessed with the Cochrane Collaboration tool for assessing the risk of bias, as suggested in the Cochrane Handbook for Systematic Reviews of Interventions (version 6.2). The currently recommended riskof-bias tools, such as the RoB 2 tool for randomized trials and the ROBINS-I tool for non-randomized studies, were used [20,21]. The critical appraisal checklist for case reports provided by the Joanna Briggs Institute (JBI) was used to perform a quality assessment of the studies [22].

\section{Results}

A total of 131 articles were identified through database searching using combinations of keywords (PubMed $n=98$, Cochrane Library $n=0$, Web of Science $n=2$, Scopus $n=11$, CINAHL $n=20$ ). Out of 131 papers, 14 were excluded as they were duplicates, and 7 were discarded because they were written in a language different from English (French $n=4$, Russian $n=2$ and Dutch $n=1$ ). A total of 110 articles were further reviewed, assessing the coherency of titles and abstracts with the aim of the present review. During 
this stage, 67 records were excluded, due to several reasons: wrong population (e.g., studies on cadavers and on animal models), wrong study design (e.g., letters, commentaries and systematic reviews), wrong outcome (e.g., needle breakage). After abstract reviews, 43 articles were selected for further inspection. Out of 43 papers, 8 were not retrieved and, for this reason, excluded from the review. Thirty-five articles were assessed for eligibility. A total of 20 papers were excluded because they did not meet the inclusion criteria (wrong publication type $n=11$; wrong outcome $n=8$; wrong population $n=1$ ). A total of 15 articles were included in the present systematic review (Figure 1).

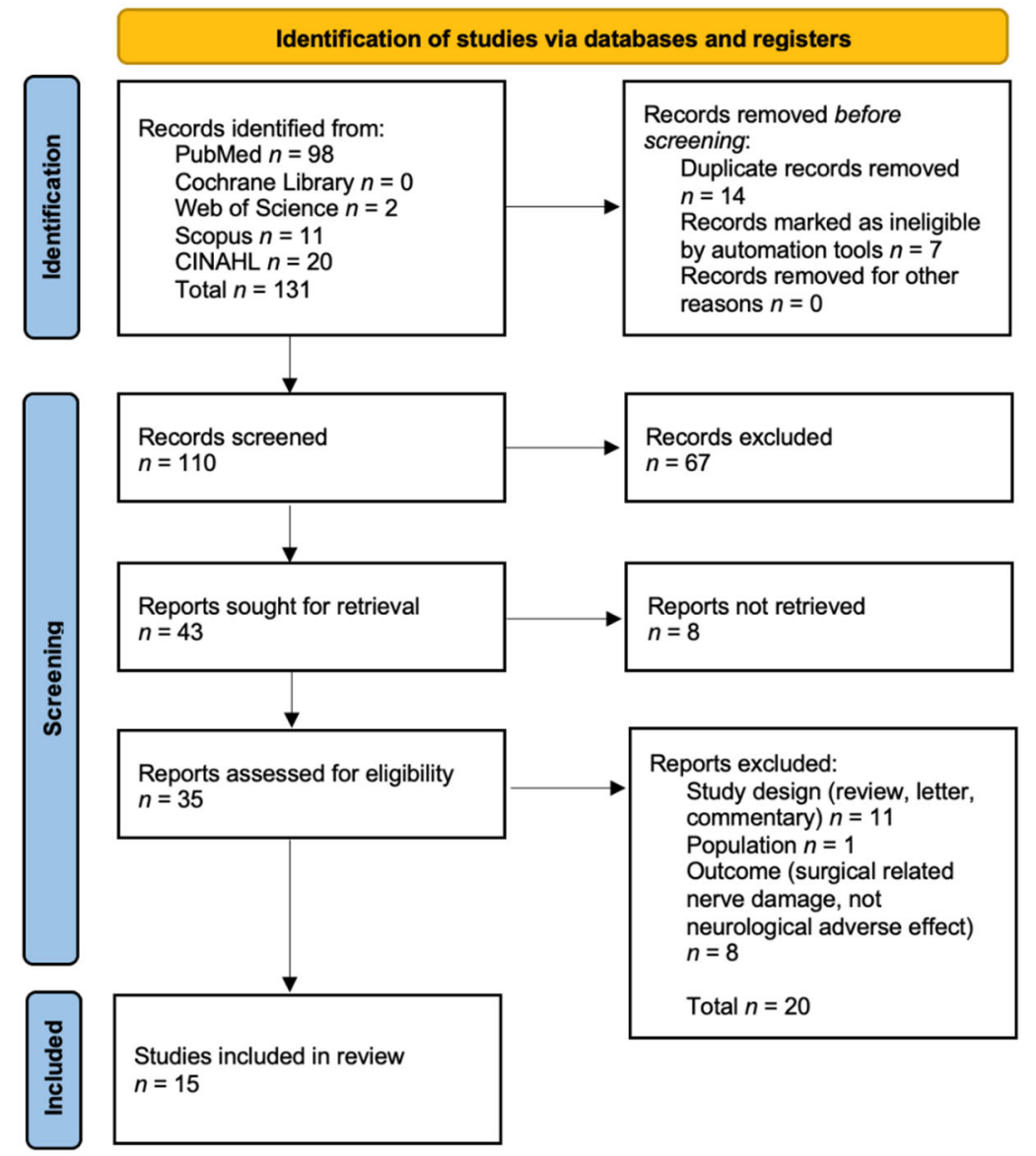

Figure 1. The flowchart of the search results and selected studies was constructed on the basis of the Preferred Reporting Items for Systematic Reviews and Meta-Analyses (PRISMA) flowchart [23].

The studies included in the present review were conducted in nine different countries: the USA $(n=4)$, Australia $(n=2)$, Canada $(n=2)$, Denmark $(n=2)$, France $(n=1)$, Germany $(n=1)$, India $(n=1)$, Italy $(n=1)$ and Japan $(n=1)$. Full-text articles that met the eligibility criteria are included in Table 1 . Overall, nine retrospective studies, as well as two prospective studies, three case reports and one case series, were included in the present systematic review. 
Table 1. Summary of the studies included in the review (list of abbreviations: $\mathrm{LN}=$ lingual nerve; $\mathrm{IAN}=$ inferior alveolar nerve; $\mathrm{ADR}=$ adverse drug reaction; NSD = neurosensory disturbance; $\mathrm{EGM}=$ electrogustometry; $\mathrm{FPD}=$ filter paper disk; $\mathrm{F}=$ female; $\mathrm{M}=$ male).

\begin{tabular}{|c|c|c|c|c|c|c|c|c|}
\hline Author (Year) & Country & StudyDesign & Aim & Sample Size & Age (Years) & Drug & Main Outcome & Secondary Outcome \\
\hline $\begin{array}{l}\text { Krafft and Hickel (1994) } \\
\text { [24] }\end{array}$ & Germany & $\begin{array}{c}\text { Prospective Study } \\
(1987-1990)\end{array}$ & $\begin{array}{l}\text { To investigate the amount of } \\
\text { damage to the LN by mandibular } \\
\text { block anesthesia alone. }\end{array}$ & $\begin{array}{c}12,104 \text { block anesthetics (5637 in } \\
\text { Fand } 6467 \text { in M) }\end{array}$ & & 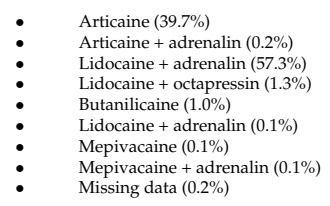 & $\begin{array}{ll}\text { - Immediate electric shock sensation } & \text { upon needle insertion in } 876 \\
& \text { patients. } \\
\text { Rate of } \\
\text { Rate of } 0.15 \% \text { of lingual sensory } \\
\text { disturbance. }\end{array}$ & 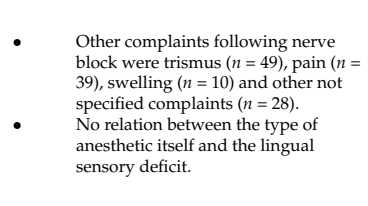 \\
\hline $\begin{array}{l}\text { Pogrel and Tamby (2000) } \\
{[25]}\end{array}$ & USA & Prospective Study & $\begin{array}{l}\text { To report what appeared to be } \\
\text { permanent nerve involvement } \\
\text { after receiving an IAN block }\end{array}$ & $\begin{array}{c}83 \\
\text { (55 and } 28 \mathrm{M} \text { ) }\end{array}$ & $\begin{array}{c}41.2 \\
\text { (range: 21-83) }\end{array}$ & 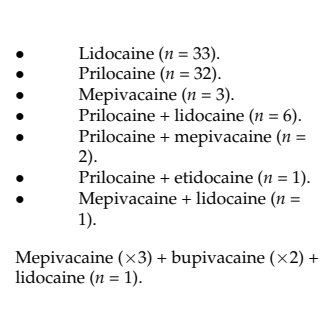 & 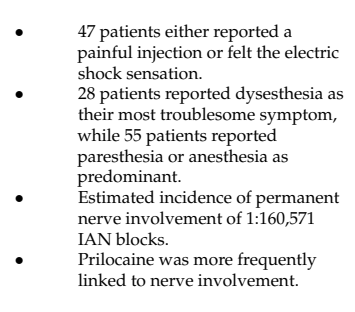 & 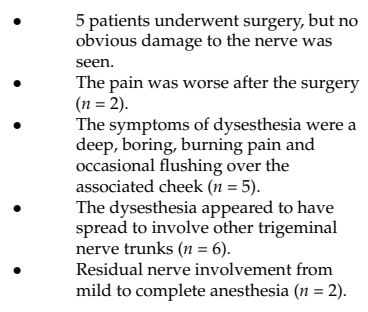 \\
\hline $\begin{array}{l}\text { Harn and Durham (1990) } \\
\text { [26] }\end{array}$ & USA & $\begin{array}{l}\text { Retrospective Study } \\
\text { (Clinical Survey) }\end{array}$ & $\begin{array}{l}\text { To investigate the incidence of } \\
\text { LN trauma and its associated } \\
\text { complications when the } \\
\text { conventional mandibulab block } \\
\text { technique is used. }\end{array}$ & $\begin{array}{l}2289 \text { adults } \\
(1245 \mathrm{~F}, 1044 \mathrm{M})\end{array}$ & 32.1 (F) and $31.9(\mathrm{M})$ & $\begin{array}{l}\text { A total of } 9587 \text { mandibular block } \\
\text { injections were performed. }\end{array}$ & 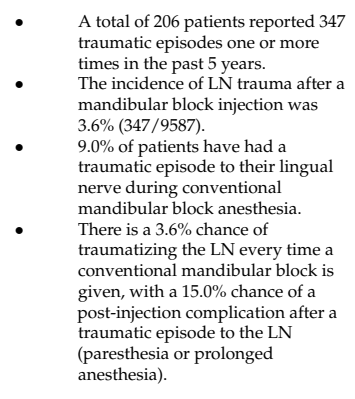 & 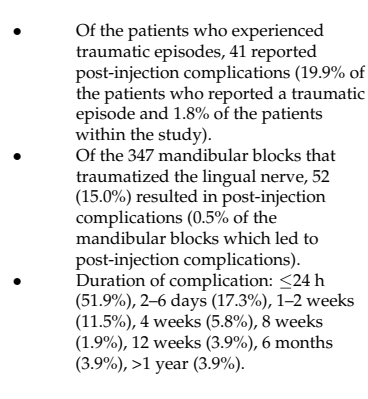 \\
\hline Pogrel et al. (1995) [27] & USA & $\begin{array}{l}\text { Retrospective Study } \\
\text { (1988-1992) }\end{array}$ & $\begin{array}{l}\text { To report cases in which altered } \\
\text { sensation occurred following } \\
\text { injection of a local anesthetic. }\end{array}$ & $12(4 \mathrm{~F}$ and $8 \mathrm{M})$ & $\begin{array}{c}40 \\
\text { (range: 22-67) }\end{array}$ & $\begin{array}{ll}\text { - } & 2 \% \text { lidocaine with 1:100,000 } \\
\text { - } & \text { epinephrin }(n=8) . \\
& 4 \% \text { prilocaine with 1:200,000 } \\
\text { e pinephrine }(n=3) . \\
\text { - } & 2 \% \text { mepivacaine with 1:20,000 } \\
& \text { levonordefrin }(n=1) .\end{array}$ & 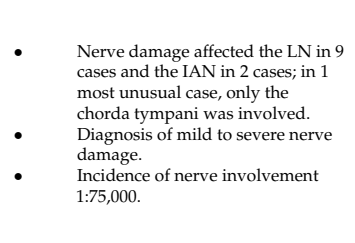 & 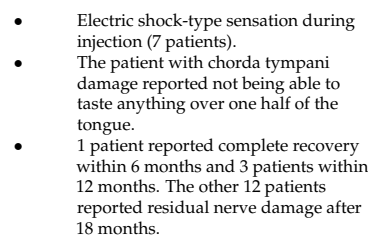 \\
\hline
\end{tabular}


Table 1. Cont.

\begin{tabular}{|c|c|c|c|c|c|c|c|c|}
\hline Author (Year) & Country & StudyDesign & Aim & Sample Size & Age (Years) & Drug & Main Outcome & Secondary Outcome \\
\hline $\begin{array}{l}\text { Hillerup and Jensen (2006) } \\
\text { [28] }\end{array}$ & Denmark & $\begin{array}{l}\text { Retrospective Study } \\
\quad(1997-2004)\end{array}$ & $\begin{array}{ll}\text { - } & \text { To clarify the magnitude } \\
\text { of sensory impairment } \\
\text { and the character of } \\
\text { signs and symptoms in } \\
\text { patients suffering } \\
\text { sensory dysfunction } \\
\text { after mandibular block } \\
\text { analgesia. } \\
\text { To follow and describe } \\
\text { the level of } \\
\text { function/dysfunction } \\
\text { over time. } \\
\text { To describe possible } \\
\text { differences related to } \\
\text { type of analgesic agent. }\end{array}$ & $\begin{array}{c}52 \\
(35 \mathrm{~F} \text { and } 17 \mathrm{M})\end{array}$ & $\begin{array}{c}47 \\
\text { (range: 24-81) }\end{array}$ & 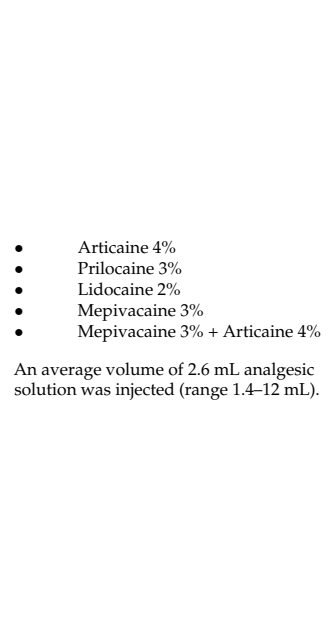 & 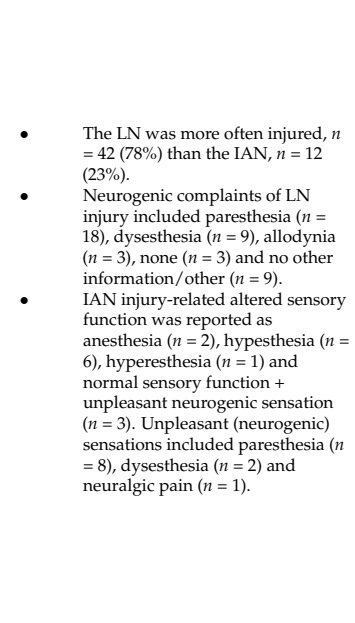 & 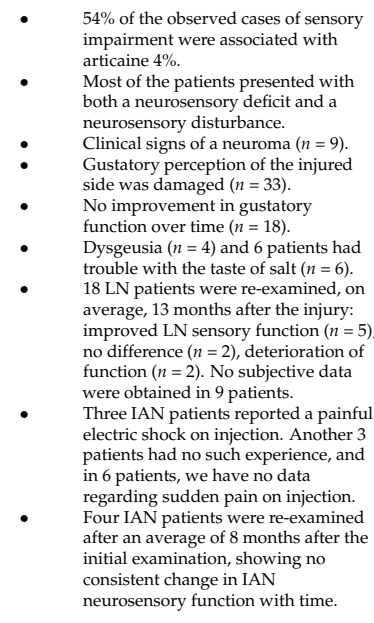 \\
\hline $\begin{array}{l}\text { Gaffen and Haas (2009) } \\
{[229]}\end{array}$ & Canada & $\begin{array}{c}\text { Retrospective Study } \\
\quad(1999-2008)\end{array}$ & $\begin{array}{l}\text { To analyze cases of paresthesia } \\
\text { associated with local anesthetic } \\
\text { injection. }\end{array}$ & $\begin{array}{c}182 \\
\text { (93 F and } 89 \mathrm{M})\end{array}$ & $\begin{array}{c}43.8 \\
\text { (range: 11-80) }\end{array}$ & 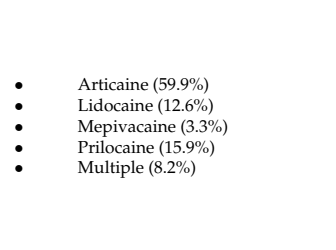 & $\begin{array}{ll}\text { - The approximate incidence of } \\
\text { non-surgical paresthesia in } \\
\text { dentistry is 1:609,000. } \\
\text { Injury solely to the LN occurred } \\
\text { significicantly more often than } \\
\text { injury solely to the IAN. }\end{array}$ & 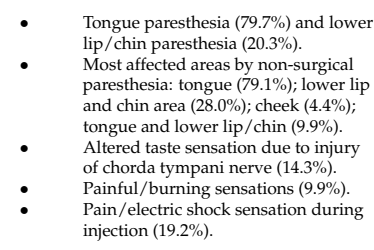 \\
\hline Garisto et al. (2010) [30] & Canada & $\begin{array}{c}\text { Retrospective Study } \\
(1997-2008)\end{array}$ & $\begin{array}{l}\text { To determine if the type of local } \\
\text { anesthetic admininittered had any } \\
\text { effect on reports of paresthesia in } \\
\text { dentistry in the United States. }\end{array}$ & 248 & $\begin{array}{c}41.9 \\
\text { (range: 15-78) }\end{array}$ & $\begin{array}{ll}: & 4 \% \text { Articaine }(51.3 \%) \\
\vdots & 4 \% \text { \%rilicaine }(42.2 \%) \\
\vdots & 2 \% \text { Lidocaine }(4.9 \%) \\
\vdots & 0.5 \% \text { Bupivacaine }(0.4 \%) \\
& 3 \% \text { Mepivacaine }(0.4 \%)\end{array}$ & 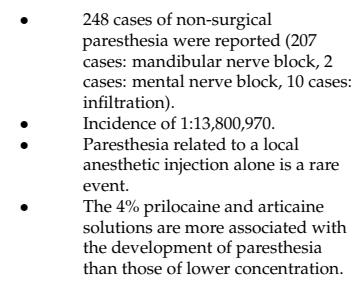 & 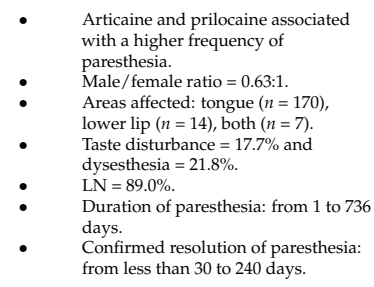 \\
\hline
\end{tabular}


Table 1. Cont.

\begin{tabular}{|c|c|c|c|c|c|c|c|c|}
\hline Author (Year) & Country & StudyDesign & Aim & Sample Size & Age (Years) & Drug & Main Outcome & Secondary Outcome \\
\hline Hillerup et al. (2011) [31] & Denmark & $\begin{array}{c}\text { Retrospective Study } \\
(1995-2007)\end{array}$ & $\begin{array}{l}\text { To report ADRs and NSDs } \\
\text { associated with injection of local } \\
\text { anesthetics. }\end{array}$ & $115(81 \mathrm{~F}$ and $34 \mathrm{M})$ & $\begin{array}{c}47 \\
\text { (range: 23-80) }\end{array}$ & $\begin{array}{ll}: & \text { Articaine } 4 \% \\
\text { Articaine and other anesthetics. } \\
\quad \text { Lidocaine } 2 \% \\
\quad \text { Mepivacaine } 3 \% \\
\text { Prilocaine } 3 \%\end{array}$ & $\begin{array}{l}\text { The NSDs affected a total of } 131 \text { branches } \\
\text { of the trigeminal nerve (ingual } n=86, \\
\text { IAN } n=31, \\
\text { buccal } n=8, \\
\text { infraorbital } n=4, \\
\text { mental } n=2 \text {. }\end{array}$ & 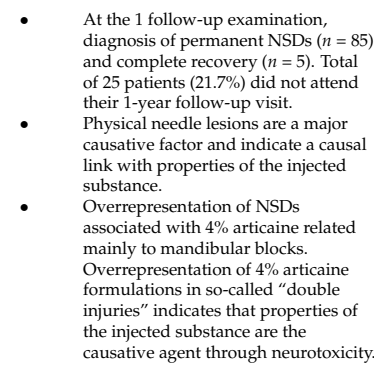 \\
\hline $\begin{array}{l}\text { Sambrook and Goss (2011) } \\
\text { [32] }\end{array}$ & Australia & $\begin{array}{l}\text { Retrospective Study } \\
(2009)\end{array}$ & $\begin{array}{l}\text { To review the literature } \\
\text { regarding nerve injuries, to } \\
\text { present recent data from South } \\
\text { Australia and to discuss the } \\
\text { management of local } \\
\text { anesthetic-related nerve injuries. }\end{array}$ & $8(4 \mathrm{~F}$ and $4 \mathrm{M})$ & 56.4 (range: 39-77) & $\begin{array}{ll}\text { : } & \text { Lidocaine. } \\
\text { Lidocaine and epinephrine } \\
1: 180,000 .\end{array}$ & $\begin{array}{l}\text { Incidence of prolonged anesthesia was 1: } \\
27,415 \text {. }\end{array}$ & $\begin{array}{ll}\text { - } & \text { All cases of prolonged anesthesia } \\
\text { related to lidocaine. } & \text { Other complaints following nerve } \\
\text { Other com } & \text { block were trismus }(n=3) \text {, pain }(n= \\
\text { 4), taste alteration }(n=2), \text { burning } \\
\text { sensation }(n=2), \text { numbness }(n=6) \\
\text { Six patients had resolution by } 3 \\
\text { months, } 2 \text { patients had persistent } \\
\text { altered sensation. }\end{array}$ \\
\hline Pogrel (2012) [33] & USA & $\begin{array}{l}\text { Retrospective Study } \\
(2006-2011)\end{array}$ & $\begin{array}{l}\text { To analyze cases of IAN and/or } \\
\text { LN damage resulting from an } \\
\text { IAN block. }\end{array}$ & 41 & - & $\begin{array}{ll}: & \text { Articaine } \\
\vdots & \text { Lidocaine } \\
& \text { Prilocaine } \\
& \text { Carbocaine }\end{array}$ & $\begin{array}{l}\text { The symptoms included } \\
\text { paresthesia and dysesthesias, varying from } \\
\text { mild to severe, but there were no cases of } \\
\text { total anesthesia. }\end{array}$ & $\begin{array}{l}\text { - Prilocaine is associated with } 34 \% \text { of } \\
\text { cases, articaine with } 33 \% \text { and } \\
\text { lidocaine with } 25 \% \text {. } \\
\text { IAN blocks can cause permanent } \\
\text { nerve damage with any local } \\
\text { anesthetic, but the incidences may } \\
\text { vary. }\end{array}$ \\
\hline Piccinni et al. (2015) [34] & Italy & $\begin{array}{l}\text { Retrospective Study } \\
\quad(2004-2011)\end{array}$ & $\begin{array}{l}\text { To evaluate the possible alert } \\
\text { signals of paresthesia by local } \\
\text { anesthetics. }\end{array}$ & $\begin{array}{c}17,246 \\
\mathrm{ADR}\end{array}$ & - & $\begin{array}{c}\text { Lidocaine, } \\
\text { bupivacaine, } \\
\text { articaine, } \\
\text { combinations of local } \\
\text { anesthetics, } \\
\text { prilocaine, } \\
\text { ropivacaine, } \\
\text { mepivacaine, } \\
\text { cocaine, capsaicin, benzocine, phenol, } \\
\text { levobupivacaine, tetracaine, procaine, } \\
\text { dyclonine, ethyl chloride, other local } \\
\text { anesthetics }\end{array}$ & $\begin{array}{l}\text { Paresthesia represented } 46.9 \% \text { of all local } \\
\text { anesthetic-related reports, burning } \\
\text { sensation } 22.2 \% \% \text {, and } \\
\text { oralparesthesi } 13.9 \% \text { and } \\
\text { hypperesthesia } 5.6 \% \text {. }\end{array}$ & $\begin{array}{l}\text { The highest number of reports was } \\
\text { found for lidocaine }(n=247), \\
\text { followed by bupivacaine }(n=99), \\
\text { articaine }(n=85) \text { ) combination of } \\
\text { different local anesthetics }(n=45) \text { and } \\
\text { prilocaine }(n=30 \text { ). } \\
\text { More cases of paresthesia, oral } \\
\text { paresthesia and dysesthesias were } \\
\text { found with articaine and prilocaine. }\end{array}$ \\
\hline
\end{tabular}


Table 1. Cont.

\begin{tabular}{|c|c|c|c|c|c|c|c|c|}
\hline Author (Year) & Country & StudyDesign & Aim & Sample Size & Age (Years) & Drug & Main Outcome & Secondary Outcome \\
\hline Kingon et al. (2011) [35] & Australia & Case Series & $\begin{array}{l}\text { To illustrate the impact of this } \\
\text { prolonged anesthesia on patients' } \\
\text { quality of life. }\end{array}$ & $\begin{array}{l}5 \\
\text { (4 males and } 1 \text { females) }\end{array}$ & $56.8 \pm 8.7$ & $\begin{array}{l}\text { - Case 1,2 and 4: } 2.2 \mathrm{~mL} \\
\text { cartridge of 4\% local anesthetic. } \\
\text { - Case 3: One cartridge of } 4 \% \\
\text { local anesthetic for each side. } \\
\text { - Case 5: } 4.4 \mathrm{~mL} \text { o o 3\% local } \\
\text { anesthetic (mepivacaine } \mathrm{HCl} \text {. }\end{array}$ & 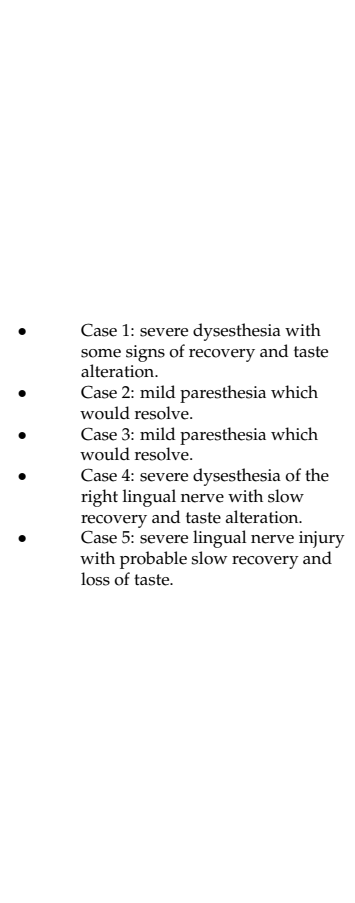 & 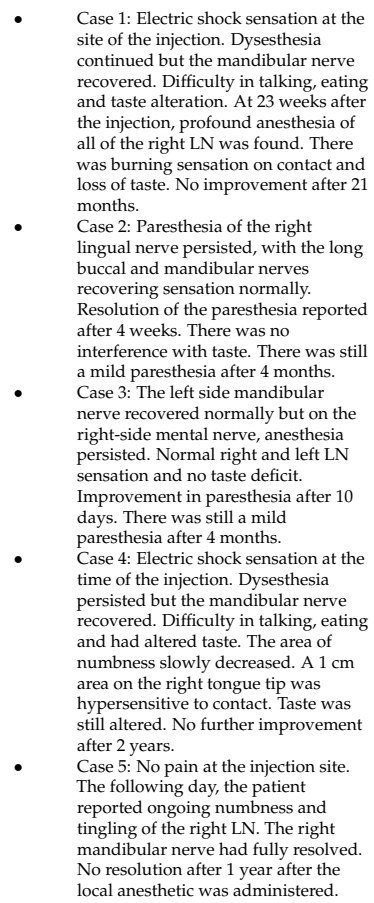 \\
\hline
\end{tabular}


Table 1. Cont.

\begin{tabular}{|c|c|c|c|c|c|c|c|c|}
\hline Author (Year) & Country & StudyDesign & Aim & $\begin{array}{l}\text { Sample Size } \\
\end{array}$ & Age (Years) & Drug & Main Outcome & Secondary Outcome \\
\hline Hotta et al. (2002) [36] & Japan & Case Report & $\begin{array}{l}\text { To report two cases of temporary } \\
\text { taste disturbance after inferior } \\
\text { alveolar nerve block. }\end{array}$ & $2(\mathrm{~F})$ & $31.5 \pm 13.4$ & - & $\begin{array}{l}\text { - Case 1: Taste disturbance and } \\
\text { burning sensation on the left side } \\
\text { of her tonguue. } \\
\text { Case 2 Numbses and taste } \\
\text { disturbance on the right side of the } \\
\text { tongue. }\end{array}$ & 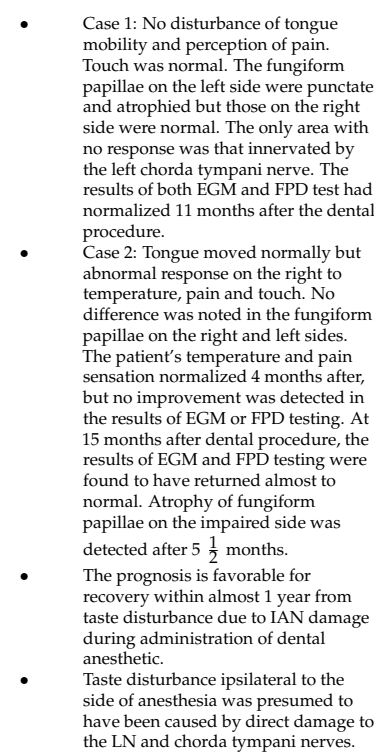 \\
\hline Chevalier et al. (2010) [37] & France & Case Report & $\begin{array}{l}\text { To describe a case of complete } \\
\text { unilateral Bell's palsy. }\end{array}$ & $1(35$ weeks pregnant $\mathrm{F})$ & 34 & $1.8 \mathrm{~mL}$ of chlorhydrate of mepivacaine & Diagnosis of Bell's palsy. & $\begin{array}{l}\text { - Two hours after the IAN block, } \\
\text { patient experienced paralysis of the } \\
\text { leff-sided facial muscles. } \\
\text { After } 1 \text { year, subtotolal recovery with } \\
\text { persistent slight muscular stiffness } \\
\text { was assessed. }\end{array}$ \\
\hline Bendgude et al. (2011) [38] & India & Case Report & $\begin{array}{l}\text { To report a complication of } \\
\text { self-inflicted injury following } \\
\text { IAN block. }\end{array}$ & $1(\mathrm{M})$ & 4 & - & Prolonged anesthesia. & $\begin{array}{l}\text { - Ulcerative lesion of the lower lip and } \\
\text { scratch injury on the chin due to the } \\
\text { numbness caused by the IAN block } \\
\text { (healing after } 2 \text { weeks). }\end{array}$ \\
\hline
\end{tabular}




\subsection{Prospective Studies}

According to Krafft and Hickel, 18 patients out of 12,104 (0.15\%) showed a lingual sensory disturbance, with a complete recovery after 6 months in $94.5 \%$ of the cases. Moreover, $1.04 \%$ of the patients included in that study complained of other disturbances such as trismus $(0.4 \%)$, lasting pain in the area of treatment $(0.3 \%)$ or swelling of the cheek $(0.08 \%)$. In $0.08 \%$ of the cases, lingual sensory disturbances and pain arose at the same time [24]. An estimated incidence of permanent nerve involvement of 1:160,571 inferior alveolar nerve blocks was reported in the study by Pogrel and Tamby [25]. In this study, the LN was affected in $79 \%$ of patients and the IAN in $21 \%$ of patients. Moreover, $56.6 \%$ of the patients experienced a very painful injection or felt an electric shock sensation during the inferior alveolar nerve block injection, while $30.1 \%$ reported no discomfort during the injection. When considering the reported symptoms, most of the patients (66.3\%) complained of paresthesia or anesthesia as the most annoying symptom, while others $(30.1 \%)$ reported dysesthesia as the predominant symptom.

Overall, the subjects included in both the studies received one or a combination of the following anesthetic solutions: articaine with or without epinephrin, lidocaine with or without epinephrin, lidocaine with octapressin, butanilicaine, mepivacaine with or without epinephrin, prilocaine and bupivacaine [24,25]. Prilocaine was found to be more frequently linked to cases of nerve involvement in the study by Pogrel and Tamby [25], while there was no relation between the type of anesthetic itself and the lingual sensory deficit in the study by Krafft and Hickel [24].

\subsection{Retrospective Studies}

Overall, the included studies evaluated cases of nerve damage caused by IAN block injection techniques during a 24-year-long period (1987-2011) in either children or adults. Different anesthetic solutions with different concentrations were considered with articaine, prilocaine, lidocaine, mepivacaine, bupivacaine or a combination of them being the most used ones. Four studies reported the incidence of nerve involvement related to the anesthetic injection, being 1:609,000 in the study by Gaffen and Haas [29], 1:13,800,970 in that by Garisto et al. [30], 1:750,000 in that by Pogrel et al. [27] and 1:27,415 in that by Sambrook and Goss [32]. The lingual nerve (LN) appeared to be the most damaged nerve, followed by the IAN and chorda tympani (CTN). The most common complaints related to IAN block injection techniques were: (i) paresthesia of the tongue, chin, cheek and lower lip; (ii) dysesthesia; (iii) taste disturbance (especially caused by CTN damage); (iv) allodynia; (v) prolonged anesthesia; (vi) burning sensation; (vii) hyperesthesia; (viii) pain or electric shock sensation during the injection procedure. Paresthesia and dysesthesia ranged from mild to severe, and no cases of total anesthesia were recorded [33]. Overall, either complete or partial nerve recovery may happen within more than 2 years. However, a permanent paresthesia may occur, especially if no signs of recovery appear after more than 9 months [33].

When considering the anesthetic type and its concentration, articaine and prilocaine were the two drugs mostly associated with a higher frequency of paresthesia. In particular, Garisto et al. reported that $4 \%$ anesthetic solutions (prilocaine and articaine) were more highly associated with the development of paresthesia than those of a lower concentration [30]. Moreover, anesthetic solutions with 4\% articaine caused 54\% of the observed cases of sensory impairment in the study by Hillerup and Jensen [28]. Similarly, significative overrepresentation of NSDs was associated with $4 \%$ articaine. A study reported that prilocaine was associated with $34 \%$ of cases of nerve damage, followed by articaine and lidocaine, with $33 \%$ and $25 \%$, respectively [33]. However, the risk of permanent nerve damage related to inferior alveolar nerve block may occur with any local anesthetic, with varying incidences [33]. Piccinni et al. also reported a significant disproportionality of paresthesia, oral paresthesia and dysesthesias when using articaine and prilocaine [34]. Finally, Sambrook and Goss reported that all cases of prolonged anesthesia were related to lignocaine [32]. 


\subsection{Case Series and Case Report}

Overall, cases involving five males and four females were described. Bendgude et al. reported a case of prolonged anesthesia in a 4-year-old male patient: due to the prolonged anesthesia, a ulcerative lesion of the lower lip as well as a scratch was assessed, with satisfactory healing after 2 weeks [38]. Chevalier et al. described a case of Bell's palsy in a 34-year-old female patient. Two hours after the inferior alveolar nerve block, the patient experienced a complete and fast paralysis of the left-sided facial muscles, with a subtotal recovery and a persistent slight muscular stiffness 1 year after the injection [37]. Hotta et al. presented two cases involving two females (41 and 22 years old) in which taste disturbance occurred, associated with atrophy of the fungiform papillae and either a burning sensation or a numbness sensation. The prognosis was favorable for recovery within 1 year from taste disturbance due to inferior alveolar nerve damage during administration of the dental anesthetic [36]. Finally, Kingon et al. described adverse effects that occurred in a sample of five subjects (four males and one female, mean age: $56.8 \pm 8.7$ ) who complained of dysesthesia, a severe dysesthetic sensation, a mild paresthetic sensation and taste alteration associated with other symptoms (e.g., electric shock sensation at the site of the injection, painful numbness, difficulty in talking and eating), following inferior alveolar nerve block injection. The authors argued that there is an increased risk of prolonged anesthesia of the IAN and, mostly, of the LN when higher concentrations of local anesthetic agents are used [35].

\subsection{Quality Assessment}

The quality of the studies included in the review was evaluated using the protocols described by Sterne et al. [21] and by the JBI [22]. The available literature to include in the present review article was restricted as the studies were judged to have a serious risk of bias in at least one bias domain, but not a critical bias in any domain. The case reports and the case series retrieved for this review were included in the analysis as they were evaluated as worthy to be included in the study.

\section{Discussion}

As previously stated, the IAN block anesthesia technique is a safe and common procedure used all over the world, but it is not free from complications. One of them is represented by the possible damage that may affect nerves, mostly the LN, the IAN and the CTN. Nerve damage may determine the types of alteration and degrees of sensitivity of the respective areas of innervation. Overall, trigeminal nerve lesions and their clinical consequences represent an important challenge in modern dentistry, especially in oral surgery. The relevance of the symptomatology that afflicts the patient in the case of damage to a sensitive nerve and the inevitable consequences for the professional determine the main issue of this type of lesion, especially from a medico-legal point of view.

Unfortunately, an accurate estimate of the exact incidence of the phenomenon is not possible due to the underestimation of such eventualities and the lack of reliable data on the number of anesthesia procedures performed. Moreover, the fact that some articles were older than 10 years may have limited the results of the present systematic review. However, the limitation was not imposed on the time span of publication because the authors deemed the included papers relevant for the purpose of the present study. Generally, reviews that only rely on published data may lead to poor and inconsistent outcome definitions and assessments, due to the limited information available from this type of report on incompletion or lack of specificity. Golder et al. investigated published versus unpublished studies, finding that a median of $43 \%$ of published studies reported adverse event data, in comparison to a median of $83 \%$ of unpublished studies [39]. Furthermore, the studies were retrospective, prospective, case reports and case series. Therefore, the data are difficult to quantify, as most of these injuries may be not reported. A possible explanation of this may lay in the fact that the professional tends to wait for the patient to accept the damage, in the hope that this will fade over time. Therefore, the results of 
the present systematic review should be interpreted with caution. Overall, few studies reported the incidence of nerve-related adverse effects as a result of an IAN block injection, ranging from 1:27,415 in the study by Sambrook and Goss [32] to 1:13,800,970 in that by Garisto et al. [30]. Other studies reported an estimated incidence of nerve involvement of 1 in 609,000 and 1:750,000 IAN blocks [27,29]. Both men and women may almost equally experience anesthesia-related adverse effects, with a slight predominance of female patients with post-injection paresthesia. Interestingly, even though no statistical difference was found in the injured mandibular side, there was a slight tendency for post-injection adverse effects on the side opposite to the clinician's used hand due to a greater difficulty in delivering the injection [26]. Anyway, these estimates may be underestimated as nerve damage could be not reported.

Other important aspects to consider are the type and concentration of anesthetic solution used, as these may influence the risk of nerve damage. In particular, articaine and prilocaine are considered the two drugs most commonly associated with a higher frequency of nerve disturbance, especially when $4 \%$ solutions are used. Garisto et al. indicated that $4 \%$ anesthetic solutions are more commonly associated with the development of paresthesia than those of a lower concentration [30]. Similarly, Hillerup and Jensen reported that anesthetic solutions with $4 \%$ articaine caused more than half of the observed cases of sensory impairment [28]. It was speculated that $4 \%$ formulations may cause a double nerve injury: one due to the neurotoxicity of the anesthetic agent, and the other caused by the direct trauma caused by the needle [31]. Piccinni et al. confirmed the higher rate of paresthesia, oral paresthesia and dysesthesias when using articaine and prilocaine [34]. However, a recent systematic review, aimed at comparing the efficacy and the safety of different local anesthetic agents for mandibular third molar extraction, reported that the most effective local anesthetic is $4 \%$ articaine, compared with $2 \%$ lidocaine, $0.5 \%$ bupivacaine and $1 \%$ ropivacaine. The same authors reported that lidocaine is the safest local anesthetic, although all investigated solutions can be used safely [14].

Overall, the clear mechanism of nerve injury is still debated [25]. Two different theories have been proposed, namely: the direct trauma of the injection needle to either the nerve or the intraneural blood vessels, and the neurotoxicity of the local anesthetic [40]. The first one implies the direct contact of the injection needle with the nerve, traumatizing it and determining a prolonged alteration in sensation. Once the tip of the needle contacts the bone, it may become barbed, enhancing the risk for perineurium rupture, endoneurium herniation and the transection of multiple nerve fibers and entire fascicles, especially on withdrawal [41,42]. However, the injection needle may also traumatize the intraneural blood vessels, determining an intraneural hematoma. The hemorrhage may lead to constrictive epineuritis, compressing the nerve fibers within the rigid tissue confines and causing localized neurotoxicity [27,41]. In addition, hematoma formation may determine the onset of reactive fibrosis and the formation of a scar, inhibiting the natural healing of the nerve $[26,43]$. Finally, the second theory hypothesizes that the anesthetic solution itself may cause chemical damage to the nerve, especially if it is placed intrafascicularly, causing demyelination, axonal degeneration and inflammation of the surrounding nerve fibers within the fascicles $[25,44,45]$.

Most of the subjects who experienced nerve-related adverse effects following an IAN block reported an electric shock-like or burning sensation [24-30,32,34-37]. The explanation for this type of symptomatology could be the direct contact of the injection needle with part of the nerve, but it is not indicative of permanent nerve injury [27]. In fact, while the occurrence of this type of sensation has been estimated between $1.3 \%$ and $8 \%$ of all IAN block injections, only a little more than half of the subjects suffering from a prolonged altered sensation experienced this symptom during the injection [40]. The $\mathrm{LN}$ appears to be the most involved nerve when considering nerve damage (the LN was affected in $70 \%$ of cases versus $30 \%$ of cases for the IAN). Pogrel et al. speculated that the LN and IAN differ in their fascicular pattern above the lingula, where an IAN block is performed [46]. Overall, nerves are made of parallel bundles of nerve fibers, called 
fascicles. The nerve fascicles vary in size, number and pattern among nerves and along their anatomical path. In particular, the LN may be unifascicular, being at risk of being injured more easily and permanently than a multifascicular nerve, which may have a greater recovery power [46]. Overall, nerve damage determines the onset of a range of symptoms, whose severity ranges from mild to severe, in a transient or permanent way. If a diagnosis of paresthesia is made, the clinician should examine the patient for the distribution of the sensory loss/disturbance and monitor continually. Generally, local anesthetic injection-induced IAN or LN dysfunction spontaneously reverts in 85-94\% of patients [25,47]. However, if no recovery or improvement occurs within two weeks, referral to a specialist with experience in nerve injuries is recommended [32,43]. If a subject experienced paresthesia for more than 8 weeks after the initial injury, full recovery is less probable and a permanent paresthesia may occur, if no signs of recovery appear after more than 9 months $[27,33,48]$.

\title{
5. Conclusions
}

The results of the present systematic review suggest that nerve damage following an IAN block anesthesia injection is a rare occurrence. Even if a clear mechanism of nerve injury has not been established yet, all clinicians should be aware that nerve damage may occur as a result of the direct nerve trauma of the needle, a neurotoxic effect of the used anesthetic solution and/or a combination of them. From a legal point of view, the risk of nerve damage is not usually discussed during consent prior to nerve block anesthesia, especially not for surgical treatments. The patients' information on possible nerve damage can be moderate as its occurrence is very unlikely to happen. In addition, if the patient does not receive balanced information on the risks/benefits of the procedures, the patient may decide to avoid the dental treatment due to the remote eventuality of nerve injury. However, if it occurs, it must be documented early, and clinicians should avoid denying responsibility or promise that it will resolve soon. Referral to a specialist is recommended.

\begin{abstract}
Author Contributions: Conceptualization, A.S. and L.A.; methodology, G.R. and M.M.; investigation, L.A. and L.T.; data curation, L.T. and M.C.; writing-original draft preparation, L.A. and M.M.; writing-review and editing, G.R., M.C. and A.S. All authors have read and agreed to the published version of the manuscript.
\end{abstract}

Funding: This research received no external funding.

Institutional Review Board Statement: Not applicable.

Informed Consent Statement: Not applicable.

Data Availability Statement: The datasets generated and/or analyzed during the present study are available from the corresponding author on reasonable request.

Conflicts of Interest: The authors declare no conflict of interest.

\section{References}

1. Astramskaitė, I.; Poškevičius, L.; Juodžbalys, G. Factors Determining Tooth Extraction Anxiety and Fear in Adult Dental Patients: A Systematic Review. Int. J. Oral Maxillofac. Surg. 2016, 45, 1630-1643. [CrossRef] [PubMed]

2. Cummings, D.R.; Yamashita, D.-D.R.; McAndrews, J.P. Complications of Local Anesthesia Used in Oral and Maxillofacial Surgery. Oral Maxillofac. Surg. Clin. N. Am. 2011, 23, 369-377. [CrossRef] [PubMed]

3. Haas, D.A. An Update on Local Anesthetics in Dentistry. J. Can. Dent. Assoc. 2002, 68, 546-551. [PubMed]

4. Giovannitti, J.A.; Bennett, C.R. Assessment of Allergy to Local Anesthetics. J. Am. Dent. Assoc. 1979, 98, 701-706. [CrossRef] [PubMed]

5. Gall, H.; Kaufmann, R.; Kalveram, C.M. Adverse Reactions to Local Anesthetics: Analysis of 197 Cases. J. Allergy Clin. Immunol. 1996, 97, 933-937. [CrossRef]

6. Moore, P.A.; Hersh, E.V. Local Anesthetics: Pharmacology and Toxicity. Dent. Clin. N. Am. 2010, 54, 587-599. [CrossRef]

7. Higuchi, R.; Fukami, T.; Nakajima, M.; Yokoi, T. Prilocaine- and Lidocaine-Induced Methemoglobinemia Is Caused by Human Carboxylesterase-, CYP2E1-, and CYP3A4-Mediated Metabolic Activation. Drug Metab. Dispos. Biol. Fate Chem. 2013, 41, 1220-1230. [CrossRef] 
8. Wang, Y.-H.; Wang, D.-R.; Liu, J.-Y.; Pan, J. Local Anesthesia in Oral and Maxillofacial Surgery: A Review of Current Opinion. J. Dent. Sci. 2021, 16, 1055-1065. [CrossRef]

9. Ravi Kiran, B.S.; Kashyap, V.M.; Uppada, U.K.; Tiwari, P.; Mishra, A.; Sachdeva, A. Comparison of Efficacy of Halstead, Vazirani Akinosi and Gow Gates Techniques for Mandibular Anesthesia. J. Maxillofac. Oral Surg. 2018, 17, 570-575. [CrossRef]

10. Steinkruger, G.; Nusstein, J.; Reader, A.; Beck, M.; Weaver, J. The Significance of Needle Bevel Orientation in Achieving a Successful Inferior Alveolar Nerve Block. J. Am. Dent. Assoc. 2006, 137, 1685-1691. [CrossRef]

11. Crowley, C.; Drum, M.; Reader, A.; Nusstein, J.; Fowler, S.; Beck, M. Anesthetic Efficacy of Supine and Upright Positions for the Inferior Alveolar Nerve Block: A Prospective, Randomized Study. J. Endod. 2018, 44, 202-205. [CrossRef] [PubMed]

12. Haas, D.A. Alternative Mandibular Nerve Block Techniques: A Review of the Gow-Gates and Akinosi-Vazirani Closed-Mouth Mandibular Nerve Block Techniques. J. Am. Dent. Assoc. 2011, 142 (Suppl. 3), 8S-12S. [CrossRef]

13. Tupyota, P.; Chailertvanitkul, P.; Laopaiboon, M.; Ngamjarus, C.; Abbott, P.V.; Krisanaprakornkit, S. Supplementary Techniques for Pain Control during Root Canal Treatment of Lower Posterior Teeth with Irreversible Pulpitis: A Systematic Review and Meta-Analysis. Aust. Endod. J. 2018, 44, 14-25. [CrossRef] [PubMed]

14. Camps-Font, O.; Figueiredo, R.; Sánchez-Torres, A.; Clé-Ovejero, A.; Coulthard, P.; Gay-Escoda, C.; Valmaseda-Castellón, E. Which Is the Most Suitable Local Anaesthetic When Inferior Nerve Blocks Are Used for Impacted Mandibular Third Molar Extraction? A Network Meta-Analysis. Int. J. Oral Maxillofac. Surg. 2020, 49, 1497-1507. [CrossRef] [PubMed]

15. Larocca de Geus, J.; Nogueira da Costa, J.K.; Wambier, L.M.; Maran, B.M.; Loguercio, A.D.; Reis, A. Different Anesthetics on the Efficacy of Inferior Alveolar Nerve Block in Patients with Irreversible Pulpitis: A Network Systematic Review and Meta-Analysis. J. Am. Dent. Assoc. 1939 2020, 151, 87-97.e4. [CrossRef]

16. Malamed, S.F.; Gagnon, S.; Leblanc, D. Articaine Hydrochloride: A Study of the Safety of a New Amide Local Anesthetic. J. Am. Dent. Assoc. 2001, 132, 177-185. [CrossRef]

17. Moher, D.; Shamseer, L.; Clarke, M.; Ghersi, D.; Liberati, A.; Petticrew, M.; Shekelle, P.; Stewart, L.A.; PRISMA-P Group. Preferred Reporting Items for Systematic Review and Meta-Analysis Protocols (PRISMA-P) 2015 Statement. Syst. Rev. 2015, 4, 1. [CrossRef]

18. Schardt, C.; Adams, M.B.; Owens, T.; Keitz, S.; Fontelo, P. Utilization of the PICO Framework to Improve Searching PubMed for Clinical Questions. BMC Med. Inform. Decis. Mak. 2007, 7, 16. [CrossRef]

19. Chou, R.; Aronson, N.; Atkins, D.; Ismaila, A.S.; Santaguida, P.; Smith, D.H.; Whitlock, E.; Wilt, T.J.; Moher, D. AHRQ Series Paper 4: Assessing Harms When Comparing Medical Interventions: AHRQ and the Effective Health-Care Program. J. Clin. Epidemiol. 2010, 63, 502-512. [CrossRef]

20. Sterne, J.A.C.; Savović, J.; Page, M.J.; Elbers, R.G.; Blencowe, N.S.; Boutron, I.; Cates, C.J.; Cheng, H.Y.; Corbett, M.S.; Eldridge, S.M.; et al. RoB 2: A Revised Tool for Assessing Risk of Bias in Randomised Trials. BMJ 2019, 366, 14898. [CrossRef]

21. Sterne, J.A.; Hernán, M.A.; Reeves, B.C.; Savović, J.; Berkman, N.D.; Viswanathan, M.; Henry, D.; Altman, D.G.; Ansari, M.T.; Boutron, I.; et al. ROBINS-I: A Tool for Assessing Risk of Bias in Non-Randomised Studies of Interventions. BMJ 2016, 355 , i4919. [CrossRef] [PubMed]

22. Zeng, X.; Zhang, Y.; Kwong, J.S.W.; Zhang, C.; Li, S.; Sun, F.; Niu, Y.; Du, L. The Methodological Quality Assessment Tools for Preclinical and Clinical Studies, Systematic Review and Meta-Analysis, and Clinical Practice Guideline: A Systematic Review. J. Evid. Based Med. 2015, 8, 2-10. [CrossRef] [PubMed]

23. Page, M.J.; McKenzie, J.E.; Bossuyt, P.M.; Boutron, I.; Hoffmann, T.C.; Mulrow, C.D.; Shamseer, L.; Tetzlaff, J.M.; Akl, E.A.; Brennan, S.E.; et al. The PRISMA 2020 Statement: An Updated Guideline for Reporting Systematic Reviews. Syst. Rev. 2021, 10, 89. [CrossRef] [PubMed]

24. Krafft, T.C.; Hickel, R. Clinical Investigation into the Incidence of Direct Damage to the Lingual Nerve Caused by Local Anaesthesia. J. Cranio-Maxillofac. Surg. 1994, 22, 294-296. [CrossRef]

25. Pogrel, M.A.; Thamby, S. Permanent Nerve Involvement Resulting from Inferior Alveolar Nerve Blocks. J. Am. Dent. Assoc. 2000, 131, 901-907. [CrossRef] [PubMed]

26. Harn, S.D.; Durham, T.M. Incidence of Lingual Nerve Trauma and Postinjection Complications in Conventional Mandibular Block Anesthesia. J. Am. Dent. Assoc. 1990, 121, 519-523. [CrossRef]

27. Pogrel, M.A.; Bryan, J.; Regezi, J. Nerve Damage Associated with Inferior Alveolar Nerve Blocks. J. Am. Dent. Assoc. 1995, 126, 1150-1155. [CrossRef]

28. Hillerup, S.; Jensen, R. Nerve Injury Caused by Mandibular Block Analgesia. Int. J. Oral Maxillofac. Surg. 2006, 35, 437-443. [CrossRef]

29. Gaffen, A.S.; Haas, D.A. Retrospective Review of Voluntary Reports of Nonsurgical Paresthesia in Dentistry. J. Can. Dent. Assoc. $2009,75,579$.

30. Garisto, G.A.; Gaffen, A.S.; Lawrence, H.P.; Tenenbaum, H.C.; Haas, D.A. Occurrence of Paresthesia after Dental Local Anesthetic Administration in the United States. J. Am. Dent. Assoc. 2010, 141, 836-844. [CrossRef]

31. Hillerup, S.; Jensen, R.H.; Ersbøll, B.K. Trigeminal Nerve Injury Associated with Injection of Local Anesthetics: Needle Lesion or Neurotoxicity? J. Am. Dent. Assoc. 2011, 142, 531-539. [CrossRef] [PubMed]

32. Sambrook, P.; Goss, A. Severe Adverse Reactions to Dental Local Anaesthetics: Prolonged Mandibular and Lingual Nerve Anaesthesia. Aust. Dent. J. 2011, 56, 154-159. [CrossRef] [PubMed]

33. Pogrel, M.A. Permanent Nerve Damage from Inferior Alveolar Nerve Blocks: A Current Update. J. Calif. Dent. Assoc. 2012, 40, 795-797. [PubMed] 
34. Piccinni, C.; Gissi, D.B.; Gabusi, A.; Montebugnoli, L.; Poluzzi, E. Paraesthesia after Local Anaesthetics: An Analysis of Reports to the FDA Adverse Event Reporting System. Basic Clin. Pharmacol. Toxicol. 2015, 117, 52-56. [CrossRef] [PubMed]

35. Kingon, A.; Sambrook, P.; Goss, A. Higher Concentration Local Anaesthetics Causing Prolonged Anaesthesia. Do They? A Literature Review and Case Reports. Aust. Dent. J. 2011, 56, 348-351. [CrossRef] [PubMed]

36. Hotta, M.; Endo, S.; Tomita, H. Taste Disturbance in Two Patients after Dental Anesthesia by Inferior Alveolar Nerve Block. Acta Oto-Laryngol. 2002, 122, 94-98. [CrossRef]

37. Chevalier, V.; Arbab-Chirani, R.; Tea, S.H.; Roux, M. Facial Palsy after Inferior Alveolar Nerve Block: Case Report and Review of the Literature. Int. J. Oral Maxillofac. Surg. 2010, 39, 1139-1142. [CrossRef]

38. Bendgude, V.; Akkareddy, B.; Jawale, B.A.; Chaudhary, S. An Unusual Pattern of Self-Inflicted Injury after Dental Local Anesthesia: A Report of 2 Cases. J. Contemp. Dent. Pract. 2011, 12, 404-407. [CrossRef]

39. Golder, S.; Loke, Y.K.; Wright, K.; Norman, G. Reporting of Adverse Events in Published and Unpublished Studies of Health Care Interventions: A Systematic Review. PLoS Med. 2016, 13, e1002127. [CrossRef]

40. Smith, M.H.; Lung, K.E. Nerve Injuries after Dental Injection: A Review of the Literature. J. Can. Dent. Assoc. 2006, 72, 559-564.

41. Stacy, G.C.; Hajjar, G. Barbed Needle and Inexplicable Paresthesias and Trismus after Dental Regional Anesthesia. Oral Surg. Oral Med. Oral Pathol. 1994, 77, 585-588. [CrossRef]

42. Crean, S.J.; Powis, A. Neurological Complications of Local Anaesthetics in Dentistry. Dent. Update 1999, 26, 344-349. [CrossRef]

43. Ruggiero, S.L. Trigeminal Nerve Injury and Repair. N. Y. State Dent. J. 1996, 62, 36-40. [PubMed]

44. Saray, A.; Apan, A.; Kisa, U. Free Radical-Induced Damage in Experimental Peripheral Nerve Injection Injury. J. Reconstr. Microsurg. 2003, 19, 401-406. [CrossRef] [PubMed]

45. Hopman, A.J.G.; Baart, J.A.; Brand, H.S. Articaine and Neurotoxicity-A Review. Br. Dent. J. 2017, 223, 501-506. [CrossRef]

46. Pogrel, M.A.; Schmidt, B.L.; Sambajon, V.; Jordan, R.C.K. Lingual Nerve Damage Due to Inferior Alveolar Nerve Blocks: A Possible Explanation. J. Am. Dent. Assoc. 2003, 134, 195-199. [CrossRef]

47. Kushnerev, E.; Yates, J.M. Evidence-Based Outcomes Following Inferior Alveolar and Lingual Nerve Injury and Repair: A Systematic Review. J. Oral Rehabil. 2015, 42, 786-802. [CrossRef]

48. Pogrel, M.A.; Kaban, L.B. Injuries to the Inferior Alveolar and Lingual Nerves. J. Calif. Dent. Assoc. 1993, 21, 50-54. 